(2) Open Access Full Text Article

SHORT REPORT

\title{
Appropriateness of administration of nasogastric medication and preliminary intervention
}

This article was published in the following Dove Press journal:

Therapeutics and Clinical Risk Management

19 November 2012

Number of times this article has been viewed

\author{
Ling-Ling Zhu' \\ Ling-Cheng $X u^{2}$ \\ Hui-Qin Wang ${ }^{3}$ \\ Jing-Fen Jin ${ }^{3}$ \\ Hua-Fen Wang ${ }^{3}$ \\ Quan Zhou ${ }^{2}$ \\ 'Cadre Department, ${ }^{2}$ Department of \\ Pharmacy, ${ }^{3}$ Division of Nursing, the \\ Second Affiliated Hospital, School \\ of Medicine, Zhejiang University, \\ Hangzhou, Zhejiang Province, China
}

Correspondence: Quan Zhou

Department of Pharmacy, the Second Affiliated Hospital, School of Medicine,

Zhejiang University, Zhejiang 310009 ,

China

Tel +8657187784615

Fax +86 57I 87022776

Email zhouquan142602@zju.edu.cn
Abstract: A utilization study was performed in a 2200-bed tertiary care teaching hospital. Data mining was performed on all nasogastric medication prescriptions for patients hospitalized in 2011. Nurses were interviewed by questionnaire. A PDCA (Plan-Do-Check-Act) cycle was used for continuous quality improvement. The proportion of patients with nasogastric tubes (NGT) was $3.2 \%$. A large number of medical orders $(n=6261)$ involved nasogastric medications with a package insert particularly noting that they should not be crushed or opened (group 1) or medications without a specific formulation recommendation in the package insert but having evidence discouraging NGT dosing (group 2). Of the nasogastrically administered sustained-release or controlled-release formulations, a sustained-release sodium valproate tablet formulation was the most prescribed drug and a sustained-release $2.5 \mathrm{mg}$ felodipine tablet was prescribed with the highest proportion of NGT dosing $[\mathrm{NGT} /(\mathrm{NGT}+$ oral $)=12.3 \%$ ]. Among the nasogastrically administered enteric-coated formulations, a myrtol-standardized enteric-coated capsule formulation was the most prescribed drug and a pantoprazole tablet formulation was prescribed with the highest proportion of NGT dosing $[\mathrm{NGT} /(\mathrm{NGT}+\mathrm{oral})=19.3 \%]$. Proportions of NGT dosing for amiodarone and carbamazepine (group 2) were $4.8 \%$ and $6.3 \%$, respectively. The percentage of nurses with adequate knowledge about pharmaceutical dosage formulations was $60 \%$. The rate of answering correctly as to whether medications in group 1 could be crushed or opened was only $30 \%$. Awareness of evidence discouraging NGT dosing of medications in group 2 was zero. Most nurses (90\%) left physicians and pharmacists with the entire responsibility for knowledge and decision-making concerning route of drug administration. After a 3-month preliminary intervention, irrational medical orders involving nasogastric administration of medications in group 1 were successfully abolished. The rate of answering correctly as to whether medications in group 1 could be crushed or opened increased to $100 \%$. This utilization study indicates poor awareness concerning nasogastric administration of medication on the part of physicians and nurses, and preliminary intervention measures were efficient in improving knowledge through team cooperation and effort.

Keywords: nasogastric tube, rational drug use, drug administration routes, drug absorption, pharmaceutical preparations, nursing

\section{Introduction}

Gastric intubation via the nasal passage (ie, nasogastric route) is a common procedure that provides access to the stomach for diagnostic and therapeutic purposes. Nasogastric tubes (NGT) are commonly used in hospitals and home care situations for administering medications to individuals who are unable to swallow safely. Suspensions for NGT dosing are usually prepared extemporaneously from crushed tablets or pellets in opened capsules. However, the package inserts for almost all enteric-coated, sustained-release, 
and controlled-release solid formulations recommend that these medications should not be crushed or opened to avoid compromising their physicochemical, biopharmaceutical, and pharmacological properties. A case of fatality due to nasogastric administration of a crushed controlled-release nifedipine tablet has provided a severe lesson in this regard. ${ }^{1}$ Many considerations should be taken into account before starting any pharmacological therapy via NGT.

The literature in recent years has shown that some products (eg, enteric-coated aspirin tablets) can be crushed and given via NGT despite their package inserts still not recommending such maneuvres. ${ }^{2,3}$ In contrast, the package inserts for some drugs, eg, amiodarone and atenolol, make no specific formulation recommendations, but there is evidence in the PubMed database discouraging NGT dosing of these medications. ${ }^{4,5}$

Medical orders involving pharmacotherapy via NGT are handled by a team consisting of physicians, pharmacists, and nurses. Inappropriate prescribing behavior and incorrect procedures used for extemporaneous preparation of an oral suspension given via NGT may result in significant harm. To guarantee the safety and efficacy of administration of medication as required by the Joint Commission International, it is necessary to rationalize clinical practice for administration of nasogastric medication. This utilization study focuses on evaluating the appropriateness of medical orders and administration procedures related to NGT and aims to increase awareness of rational drug use via NGT, emphasizing the importance of education and communication between team members on basic knowledge concerning pharmaceutical formulations and the procedure for nasogastric drug administration, finding new perspectives, and promoting relevant research in this respect.

\section{Materials and methods Data collection}

This utilization study was performed in a 2200-bed tertiary care teaching hospital. Full prescribing information from each oral medication in this hospital was reviewed for any data indicating that the medication could not be crushed or opened. A search was performed for each drug using information from the Facts and Comparisons (http://www. factsandcomparisons.com) and New Clinical Drug Reference (http://www.medscape.com.cn) databases. A PubMed search was completed using the search terms "nasogastric" AND "medication" and "nasogastric" AND "bioavailability".

Using Visual FoxPro version 9.0, an informatics pharmacist collected prescribing data from the hospital information system. Drugs related to NGT dosing were divided into four groups (Table 1). Two clinical pharmacists performed a retrospective prescription audit of all investigated medical orders in 2011.

One hundred and fifty clinical nurses were interviewed in March 2012 by questionnaire which contained five topics (Figure 1) on basic technical knowledge of pharmaceutical formulations, with questions concerning whether each medication in Table 1 could be crushed or opened, how the suspensions are prepared extemporaneously and given, case reports of adverse events, such as tube obstruction, demands for help from pharmacists, and establishing a standard operating procedure related to drug administration via NGT.

Table I List of drugs related to nasogastric tube dosing in this study

\begin{tabular}{|c|c|}
\hline Group & Generic name \\
\hline \multirow[t]{24}{*}{ Group I } & SR or CR formulations \\
\hline & Sodium valproate SR tablets (Depakin $\left.{ }^{\circledR}\right)$, felodipine \\
\hline & SR (Plendil ${ }^{\circledR}$ ) $2.5 \mathrm{mg}$ and $5 \mathrm{mg}$ tablets, metoprolol \\
\hline & succinate SR tablets $\left(\right.$ ZOK Betaloc $\left.{ }^{\circledR}\right)$, nifedipine CR \\
\hline & tablets $\left(\right.$ Adalat $\left.^{\circledR}\right)$, nifedipine SR tablets, indapamide \\
\hline & SR tablets $\left(\right.$ Natrilix $\left.^{\circledR}\right)$, verapamil hydrochloride SR \\
\hline & tablets, isosorbide mononitrate SR tablets, gliclazide \\
\hline & CR tablets (Diamicron ${ }^{\circledR}$ MR), glipizide CR tablets \\
\hline & (Glucotrol $\mathrm{XL}^{\circledR}$ ), potassium chloride SR tablets, \\
\hline & tamsulosin hydrochloride SR capsules $\left(\operatorname{Harnal}^{\circledR}\right)$, \\
\hline & mizolastine SR tablets (Mizollen ${ }^{\circledR}$ ), theophylline SR \\
\hline & tablets, indomethacin SR tablets, diclofenac sodium \\
\hline & SR capsules, tramadol hydrochloride SR tablets, \\
\hline & paracetamol SR tablets $\left(\right.$ Tylenol $\left.^{\circledR}\right)$ \\
\hline & EC formulations \\
\hline & Myrtol-standardized EC capsules \\
\hline & (GeloMyrtol ${ }^{\circledR}$ Forte), omeprazole magnesium EC \\
\hline & tablets (Losec MUPS ${ }^{\circledR}$ ), pantoprazole sodium EC \\
\hline & capsules, pantoprazole EC tablets (Pantoloc ${ }^{\circledR}$ ), \\
\hline & rabeprazole sodium EC tablets, bisacodyl EC tablets, \\
\hline & duloxetine hydrochloride EC capsules $\left(\right.$ Cymbalta $\left.^{\circledR}\right)$ \\
\hline & Miscellaneous formulations \\
\hline & Pinaverium bromide tablets $\left(\right.$ Dicete $^{\circledR}{ }^{\circledR}$ ), rosiglitazone \\
\hline & maleate tablets $\left(\right.$ Avandia $\left.^{\circledR}\right)$ \\
\hline \multirow[t]{2}{*}{ Group 2} & Atenolol tablets, amiodarone hydrochloride tablets \\
\hline & $\left(\right.$ Cordarone $\left.^{\circledR}\right)$, carbamazepine tablets $\left(\right.$ Tegreto $\left.^{\circledR}\right)$ \\
\hline \multirow[t]{4}{*}{ Group 3} & Aspirin EC tablets (Bayaspirin ${ }^{\circledR}$ ), aspirin EC capsules \\
\hline & $\left(\right.$ Bokey ${ }^{\circledR}$ ), carbidopa and levodopa CR tablets \\
\hline & $\left(\right.$ Sinemet $\left.C R^{\circledR}\right)$, esomeprazole magnesium EC \\
\hline & tablets $\left(\right.$ Nexium $\left.{ }^{\circledR}\right)$ \\
\hline Group 4 & Clopidogrel hydrogen sulfate tablets (Plavix ${ }^{\circledR} 75 \mathrm{mg}$ ) \\
\hline
\end{tabular}

Notes: Group I, package insert of each drug particularly noted that the medication should not be crushed or opened; group 2, package insert of each drug has no specific formulation recommendation, but with evidence in the PubMed database discouraging NGT dosing of these medications; group 3, package insert of each drug particularly noted that the medication should not be crushed or opened, but there was evidence in the PubMed database supporting NGT dosing of these medications; group 4, package insert of each drug has no specific formulation recommendation, but there was evidence in the PubMed database supporting NGT dosing of this medication.

Abbreviations: $\mathrm{NGT}$, nasogastric tube; $\mathrm{SR}$, sustained-release; $\mathrm{CR}$, controlled-release; $\mathrm{EC}$, enteric-coated. 
Nursing unit name:

Please tick appropriate parentheses below.

1. Do you have enough knowledge on pharmaceutical dosage forms? I know it quite well ( ) I know some ( ) I am in dire need of such knowledge ( )

2. Do you have enough knowledge on whether medications can be crushed or opened? I know it quite well ( ) I know some ( ) I am in dire need of such knowledge ( )

3. Can sustained- release or controlled-release solid formulations be crushed? Yes ( ) No ( ) It depends on the kind of drug ( )

4. Can enteric-coated solid formulations be crushed? Yes ( ) No ( ) It depends on the kind of drug ( )

5. Is it necessary to establish a hospital-wide standard operation procedure for nasogastric administration? Necessary ( ) Not necessary ( )

6. Are there any tools for crushing solid medications in your nursing unit? Yes ( ) No ( ) What kind of tools? Wooden mortar ( ) Glass mortar ( ) Stone mortar ( ) Crushing the medication within its own wrap or waxed paper with a rounded edge stone ( )

7. Is it necessary for wearing gloves or hand disinfection before crushing tablets? Of course ( ) Not practical due to inconvenience ( ) It depends on the kind of drug ( )

8. Can multiple drugs be mixed to prepare oral suspensions and be administered via nasogastric tube concomitantly? They can be mixed together ( ) They should not be mixed together and administered via nasogastric tube concomitantly ( ) It depends on circumstances ( )

9. How much volume of liquid is needed for dissolution and dilution of the crushed formulation? No requirements ( ) It has special requirements otherwise the feeding tube will be obstructed ( )

10. What kinds of liquid may be used during extemporaneously preparing the suspensions for NGT administration? Normal saline ( ) tap water ( ) distilled water ( ) Juice ( )

11. Is it necessary to rinse the tube with a volume of liquid after nasogastric administration? Necessary ( ) Not necessary due to time-consuming process ( )

12. What kinds of liquid may be used to rinse the tube after nasogastric administration? Normal saline ( ) tap water ( ) distilled water ( ) juice ( )

13. Who will bear the responsibility of knowledge and decision-making concerning drug administration route? Physicians ( ) Pharmacists ( ) Nurses ( )

14. Are you hoping to get guidance from pharmacists with respect to nasogastric administration? Yes ( ) No（ )

15. Have you detected the problems such as tube obstruction, color changes and agglomeration in clinical practice of nasogastric administration? How did you deal with these problems? Please give some examples.

16. Please complete the following survey form.

\begin{tabular}{|c|l|l|}
\hline & \multicolumn{2}{|c|}{ Please tick appropriate box below } \\
\hline $\begin{array}{c}\text { Drugs as indicated in } \\
\text { Table 1 }\end{array}$ & $\begin{array}{l}\text { "Pros" (It can be administered } \\
\text { via NGT) }\end{array}$ & $\begin{array}{l}\text { "Cons" (It should not be } \\
\text { administered via NGT) }\end{array}$ \\
\hline & $\square$ & $\square$ \\
\hline & $\square$ & $\square$ \\
\hline & $\square$ & $\square$ \\
\hline
\end{tabular}

Figure I Nurse-oriented questionnaire of nasogastric medication administration.

A PDCA (Plan-Do-Check-Act) cycle was used for continuous quality improvement. ${ }^{6,7}$

\section{Statistical analysis}

A descriptive analysis was performed. The proportion of NGT dosing was calculated as NGT/(NGT + oral). Differences between patient groups were tested for statistical significance using Pearson's Chi-square test. A $P$ value $<0.05$ was considered to be statistically significant.

\section{Results}

General information on patients with NGT

Ward distribution and number of patients with an NGT are shown in Table 2. The proportion of patients receiving NGT in this hospital was $3.2 \%$. A large number of medical orders involved nasogastric medications with a package insert particularly noting that they should not be crushed or opened (group 1) or medications without a specific 
Table 2 Ward distribution and number of patients with a nasogastric tube in $201 \mathrm{I}$

\begin{tabular}{llll}
\hline Wards & Patients with NGT (n) & Patients (n) & $\begin{array}{l}\text { Ratio of number of } \\
\text { patients with NGT }\end{array}$ \\
\hline Total & 2116 & 66006 & $3.2 \%$ \\
ICU & 805 & 1686 & $47.7 \%$ \\
Non-ICU & 1311 & 64320 & $2.0 \%$ \\
Neurology, neurosurgery, & 885 & 9865 & $9.0 \% \%^{\#}$ \\
and rehabilitation wards & & & $0.8 \%$ \\
Other non-ICU wards & 426 & 54455 & \\
\hline
\end{tabular}

Notes: ${ }^{\#} P=0.000$ (ICU versus non-ICU); ${ }^{\# P}=0.000$ (neurology, neurosurgery, and rehabilitation wards versus other non-ICU wards). Differences between patient groups were tested for statistical significance using Pearson's Chi-square test. A $P$ value $<0.05$ was considered to be statistically significant.

Abbreviations: ICU, intensive care unit; NGT, nasogastric tube.

formulation recommendation in the package insert but having evidence discouraging NGT dosing (group 2). As expected, the proportion of patients with an NGT in ICU was significantly higher than in those outside ICU $(47.7 \%$ versus $2.0 \%, P=0.000$ ). Also, the proportion of patients with NGT in neurology, neurosurgery, and rehabilitation wards was significantly higher compared with other non-ICU wards (9.0\% versus $0.8 \%, P=0.000)$.

\section{Details of medical orders involving drugs administered via NGT}

Overall, the number of medical orders involving NGT was 10,341 , representing $3.0 \%$ of the total number of medical orders for the study drugs (Table 3). Drug administration via NGT was noted for each medication in Table 1 except for atenolol. A large number of medical orders $(n=6261)$ involved nasogastric administration of medications in group 1 and group 2 , ie, approximately $60 \%$ of medical orders involving NGT were not rational.

Among the sustained-release or controlled-release formulations administered nasogastrically in group 1, a sustained-release sodium valproate tablet $\left(\right.$ Depakin $\left.^{\circledR}\right)$ was the most commonly prescribed drug and a sustained-release felodipine tablet $\left(\right.$ Plendil $^{\circledR} 2.5 \mathrm{mg}$ ) was prescribed with the highest frequency of NGT dosing $[\mathrm{NGT} /(\mathrm{NGT}+$ oral $)=12.3 \%]$.

Among the nasogastrically administered enteric-coated formulations, a myrtol-standardized enteric-coated capsule (GeloMyrtol ${ }^{\circledR}$ Forte) was the most commonly prescribed drug and a pantoprazole tablet was prescribed with the highest proportion of NGT [NGT/(NGT + oral) $=19.3 \%$ ].

Numbers of medical orders involving NGT dosing of drugs in group 2 were as follows: amiodarone hydrochloride $\left(\right.$ Cordarone $\left.^{\circledR}\right)$ tablets $(n=329)$ and carbamazepine $\left(\right.$ Tegretol $\left.^{\circledR}\right)$ tablets $(n=156)$. Proportions of amiodarone and carbamazepine (group 2) that were administered via the NGT route were $4.8 \%$ and $6.3 \%$, respectively. Medical orders involving NGT dosing of atenolol were not documented in this survey. The number of medical orders involving NGT dosing for clopidogrel was 1530 , representing $5.3 \%$ of the total number of medical orders for clopidogrel.

The number of drugs given simultaneously via NGT was described for a randomly selected day. There were two patients (1.7\%) receiving more than 10 drugs, 24 patients (20.9\%) receiving 5-9 drugs, 56 patients (48.7\%) receiving 2-4 drugs, and 33 patients $(28.7 \%)$ receiving one drug via the NGT route.

\section{Questionnaire results}

Data gleaned from the questionnaire are summarized in Table 4. In addition, there were 45 case reports of adverse events, such as tube obstruction and formulation color changes in 2011. Normal saline and distilled water were usually used to prepare the suspension administered and rinse the NGT feeding tube. Ninety percent of adverse events were related to simultaneous administration via NGT after crushing and mixing multiple drugs as well as inadequate flushing.

\section{Discussion Inappropriate administration of group I and 2 drugs}

Sustained-release and controlled-release formulations contain significantly higher amounts of active drug than are present in their normal-release counterparts. The matrix containing the drug is actually a highly specialized delivery system which is destroyed by crushing. Package inserts for almost all sustained-release and controlledrelease formulations specifically note that these medications should not be crushed or opened. Table 3 lists a scheme for replacement of sustained-release or controlled-release formulations with alternatives for patients with NGT. The literature shows the adverse outcomes resulting from administration of sustained-release or controlled-release 
Table 3 Details of medical orders involving drugs administered via nasogastric tube in $20 \mathrm{II}$

\begin{tabular}{|c|c|c|}
\hline Drugs & $\begin{array}{l}\text { Proportion of medical orders } \\
\text { involving NGT dosing }\end{array}$ & Alternative \\
\hline Drugs administered via NGT & $10,313(3.0 \%)$ & \\
\hline \multicolumn{3}{|l|}{ Group I } \\
\hline \multicolumn{3}{|l|}{ SR or CR formulations } \\
\hline Sodium valproate SR tablets (Depakin ${ }^{\circledR}$ ) & $|44|(7.8 \%)$ & Intravenous valproate sodium \\
\hline Potassium chloride SR tablets & $719(1.5 \%)$ & $\begin{array}{l}\text { Intravenous potassium chloride, or } 10 \% \text { oral } \\
\text { potassium chloride solution }\end{array}$ \\
\hline Tamsulosin hydrochloride SR capsules $\left(\right.$ Harnal $\left.{ }^{\circledR}\right)$ & $232(2.4 \%)$ & $\begin{array}{l}\text { NR alpha-blockers (eg, alfuzosin, tamsulosin, } \\
\text { and terazosin) }\end{array}$ \\
\hline Isosorbide mononitrate SR tablets & $213(1.2 \%)$ & NR formulations or nitroglycerin patches \\
\hline Felodipine SR tablets (Plendil ${ }^{\circledR} 2.5 \mathrm{mg}$ ) & $187(12.3 \%)$ & $\begin{array}{l}\text { NR formulations of long-acting calcium antagonists } \\
\text { (ie, amlodipine) }\end{array}$ \\
\hline Metoprolol succinate SR tablets (ZOK Betaloc $\left.{ }^{\circledR}\right)$ & 125 (0.9\%) & Metoprolol tartrate tablets (Betaloc) \\
\hline Felodipine SR tablets (Plendil ${ }^{\circledast} 5 \mathrm{mg}$ ) & $116(1.2 \%)$ & $\begin{array}{l}\text { NR formulations of long-acting calcium antagonists } \\
\text { (ie, amlodipine) }\end{array}$ \\
\hline Nifedipine CR tablets (Adalat ${ }^{\circledR}$ ) & $100(0.5 \%)$ & $\begin{array}{l}\text { NR formulations of long-acting calcium antagonists } \\
\text { (ie, amlodipine) }\end{array}$ \\
\hline Mizolastine SR tablets (Mizollen ${ }^{\circledR}$ ) & $50(2.7 \%)$ & $\begin{array}{l}\text { NR formulations of long-acting antihistamine } \\
\text { (eg, cetirizine, fexofenadine, desloratadine) }\end{array}$ \\
\hline Nifedipine SR tablets & $43(1.8 \%)$ & $\begin{array}{l}\text { NR formulations of long-acting calcium atangonists } \\
\text { (ie, amlodipine) }\end{array}$ \\
\hline Gliclazide CR tablets (Diamicron ${ }^{\circledR}$ MR) & $28(0.6 \%)$ & $\begin{array}{l}\text { Gliclazide tablets }\left(\text { Diamicron }^{\circledR}\right)\left(80 \mathrm{mg} \text { Diamicron }^{\circledR}\right. \\
\left.\text { is equivalent to } 30 \mathrm{mg} \text { Diamicron }{ }^{\circledR} \mathrm{MR}\right)\end{array}$ \\
\hline Theophylline SR tablets & $16(0.3 \%)$ & Liquid oral formulation, or IV aminophylline \\
\hline Indapamide SR tablets $\left(\right.$ Natrilix $\left.^{\circledR}\right)$ & $\mathrm{II}(\mathrm{I} .2 \%)$ & $\begin{array}{l}\text { NR formulation ( } 1.5 \mathrm{mg} \text { SR OD is equivalent } \\
\text { to } 2.5 \mathrm{mg} \text { OD) }\end{array}$ \\
\hline Indomethacin SR tablets & II (0.3\%) & NR formulations of NSAIDs \\
\hline Diclofenac sodium SR capsules & $7(0.7 \%)$ & NR formulations of NSAIDs \\
\hline Tramadol SR tablets & $5(0.06 \%)$ & Tramadol hydrochloride dispersible tablets \\
\hline Paracetamol SR tablets $\left(\right.$ Tylenol$\left.^{\circledR}\right)$ & I (7.7\%) & NR formulations of NSAIDs \\
\hline Glipizide CR tablets (Glucotrol $\mathrm{XL}^{\circledR}$ ) & I (0.06\%) & NR formulations of glipizide \\
\hline \multicolumn{3}{|l|}{ EC formulations } \\
\hline Myrtol-standardized EC capsules (GeloMyrtol ${ }^{\circledR}$ & $1052(8.7 \%)$ & Ambroxol hydrochloride oral formulations \\
\hline \multicolumn{3}{|l|}{ Forte) } \\
\hline Pantoprazole EC tablets $\left(\right.$ Pantoloc $^{\circledR}$ ) & $455(19.3 \%)$ & $\begin{array}{l}\text { Disperse the crushed tablet into } 4.2 \% \text { sodium } \\
\text { bicarbonate solution or apple juice; or change } \\
\text { to alternative PPIs (esomeprazole, lansoprazole } \\
\text { orally disintegrating tablet or IV pantoprazole) }\end{array}$ \\
\hline Pantoprazole sodium EC capsules & $411(1.4 \%)$ & \\
\hline Omeprazole magnesium EC tablets (Losec MUPS ${ }^{\circledR}$ ) & $276(4.7 \%)$ & $\begin{array}{l}\text { Alternative PPIs (esomeprazole, lansoprazole orally } \\
\text { disintegrating tablet or IV omeprazole) }\end{array}$ \\
\hline Rabeprazole sodium EC tablets & $33(1.7 \%)$ & $\begin{array}{l}\text { Alternative PPIs (esomeprazole, lansoprazole orally } \\
\text { disintegrating tablet) }\end{array}$ \\
\hline Bisacodyl EC tablets & $38(1.8 \%)$ & Other laxatives \\
\hline Duloxetine hydrochloride EC capsules $\left(\right.$ Cymbalta $\left.^{\circledR}\right)$ & $6(0.2 \%)$ & Alternative selective serotonin reuptake inhibitors \\
\hline \multicolumn{3}{|l|}{ Miscellaneous formulations } \\
\hline Pinaverium bromide tablets $\left(\right.$ Dicetel $\left.^{\circledR}\right)$ & $125(8.1 \%)$ & \\
\hline Rosiglitazone maleate tablets $\left(\right.$ Avandia $\left.^{\circledR}\right)$ & $74(11.0 \%)$ & Pioglitazone \\
\hline \multicolumn{3}{|l|}{ Group 2} \\
\hline Amiodarone hydrochloride tablets (Cordarone ${ }^{\circledR}$ ) & 329 (4.8\%) & $\begin{array}{l}\text { Dosage need increase and therapeutic drug } \\
\text { monitoring was especially necessary during } \\
\text { NGT dosing }\end{array}$ \\
\hline Carbamazepine tablets $\left(\right.$ Tegretol $\left.^{\circledR}\right)$ & $156(6.3 \%)$ & \\
\hline \multicolumn{3}{|l|}{ Group 3} \\
\hline Aspirin EC tablets (Bayaspirin ${ }^{\circledR}$ ) & $|60|(2.6 \%)$ & \\
\hline
\end{tabular}


Table 3 (Continued)

\begin{tabular}{lll}
\hline Drugs & $\begin{array}{l}\text { Proportion of medical orders } \\
\text { involving NGT dosing }\end{array}$ & Alternative \\
\hline Esomeprazole magnesium EC tablets $\left(\right.$ Nexium $\left.^{\circledR}\right)$ & $601(5.6 \%)$ \\
Aspirin EC capsules $\left(\right.$ Bokey $\left.^{\circledR}\right)$ & $182(17.5 \%)$ \\
Carbidopa and levodopa CR tablets (Sinemet CR $\left.{ }^{\circledast}\right)$ & $138(6.6 \%)$ \\
Group 4 & \\
Clopidogrel hydrogen sulfate tablets (Plavix $\left.{ }^{\circledast} 75 \mathrm{mg}\right)$ & $1530(5.3 \%)$ \\
\hline
\end{tabular}

Notes: The proportion of NGT dosing was calculated as NGT/(NGT + oral). Group I, medications particularly noting that the medication should not be crushed or opened; group 2, medications with no specific formulation recommendations, but PubMed-based evidence for discouraging NGT dosing; group 3, medications particularly noting that the medication should not be crushed or opened, but evidence in the PubMed database supporting NGT dosing of these medications; group 4, medications with no specific formulation recommendations, but PubMed-based evidence supporting NGT dosing.

Abbreviations: NGT, nasogastric tube; SR, sustained-release; CR, controlled-release; NR, normal-release; EC, enteric-coated; OD, once daily; NSAIDs, nonsteroidal anti-inflammatory drugs; IV, intravenous; PPIs, proton pump inhibitors.

formulations via NGT. Schier et al reported a case in which a crushed controlled-release nifedipine tablet contributed to a patient fatality. ${ }^{1}$ Berkovitch et al compared pharmacokinetic parameters between frail elderly patients taking a sustained-release theophylline formulation twice daily orally $(n=17)$ and those receiving it via NGT $(n=15)$. The main pharmacokinetic values were lower in patients taking their theophylline orally as compared with patients receiving theophylline via an NGT, with trough theophylline blood levels of $3.78 \pm 3.2 \mu \mathrm{g} / \mathrm{mL}$ versus $8.63 \pm 4.6 \mu \mathrm{g} / \mathrm{mL}$ $(P<0.01)$, peak plasma levels of $6.53 \pm 4.1 \mu \mathrm{g} / \mathrm{mL}$ versus $10.51 \pm 3.30 \mu \mathrm{g} / \mathrm{mL}(P<0.01)$, and an area under the plasma concentration-time curve (AUC) of $50.04 \pm 38.59 \mu \mathrm{g} / \mathrm{mL}$ versus $80.37 \pm 28.8 \mu \mathrm{g} / \mathrm{mL}(P<0.05)$. Patients receiving the drug via NGT had more variable and unexpectedly low blood theophylline levels. ${ }^{8}$
Proton pump inhibitors are sensitive to gastric acid, so all oral formulations of proton pump inhibitors are enteric-coated. Crushing solid formulations of proton pump inhibitors is not advised by pharmaceutical manufacturers. The two methods for administering proton pump inhibitors (ie, oral and NGT dosing) may be not bioequivalent. Further, bioequivalence between the oral and NGT routes seems not to be a common feature of drugs within a similar structural class. Messaouik et al compared the behavior of three proton pump inhibitors (omeprazole, lansoprazole, and esomeprazole) during transit of the granules via NGT and studied the influence of four variables, ie, tube material (silicone or polyurethane), solvent used to dilute the granules (water or apple juice), administration pattern $(1 \times 30 \mathrm{~mL}$ or $3 \times 10 \mathrm{~mL})$, and rinse volume $(10 \mathrm{~mL}$ or $20 \mathrm{~mL}) .{ }^{9}$ The results showed complete delivery of esomeprazole through the tube, but

Table 4 Data derived from questionnaire concerning nasogastric administration before preliminary intervention

\begin{tabular}{|c|c|}
\hline Items & Data \\
\hline Percentage of nurses with adequate knowledge on pharmaceutical dosage forms & $60 \%$ \\
\hline The correct rate of answer to whether medications in group I could be crushed or opened & $30 \%$ \\
\hline Awareness rate of evidence discouraging nasogastric dosing of medications in group 2 & $0 \%$ \\
\hline $\begin{array}{l}\text { Percentage of nurses allowing the physicians and pharmacists the entire responsibility of knowledge and decision-making } \\
\text { concerning administration route }\end{array}$ & $90 \%$ \\
\hline Percentage using wood or stone mortar to crush solid formulations & $40 \%$ \\
\hline $\begin{array}{l}\text { Percentage of the means that crushing the intact tablet wrapped in a unit-dose plastic bag or a piece of waxed paper with a } \\
\text { rounded edge stone }\end{array}$ & $30 \%$ \\
\hline Percentage of nurses administering multiple drugs nasogastrically at the same time with the same syringe & $80 \%$ \\
\hline $\begin{array}{l}\text { Percentage of nurses implementing a particular administration procedure (ie, each drug is individually crushed immediately } \\
\text { before administration and individually diluted and administered, followed by rinsing the tube between medication administrations) }\end{array}$ & $8 \%$ \\
\hline Percentages of nurses wearing gloves while extemporaneously preparing the suspensions for nasogastric administration & $10 \%$ \\
\hline Percentages of different kinds of liquid used during extemporaneous preparation of suspensions for nasogastric administration & $\begin{array}{l}30 \% \text { (normal saline) } \\
70 \% \text { (distilled water) }\end{array}$ \\
\hline Percentage needing to rinse tube with a volume of liquid after nasogastric administration & $95 \%$ \\
\hline Percentages of different kinds of liquid used to rinse tube after nasogastric administration & $\begin{array}{l}30 \% \text { (normal saline) } \\
70 \% \text { (distilled water) }\end{array}$ \\
\hline Percentage of interviewed nurses hoping to get guidance from pharmacists with respect to nasogastric administration & $100 \%$ \\
\hline $\begin{array}{l}\text { Percentage needing to establish a hospital-wide standard operation procedure for nasogastric administration (ie, an updated list } \\
\text { of drugs which could not be crushed or opened, advice on how the suspensions are extemporaneously prepared and given and } \\
\text { measures for prevention of tube obstruction) }\end{array}$ & $100 \%$ \\
\hline
\end{tabular}


average losses for omeprazole and lansoprazole of $39 \%$ and $33 \%$, respectively. Esomeprazole is thus the preferred proton pump inhibitor for patients with an NGT. Use of omeprazole is not recommended because an adequate therapeutic concentration of active ingredient cannot be guaranteed. With respect to lansoprazole, rinse volume and tube material both had a significant influence (ie, a $20 \mathrm{~mL}$ rinse improved the drug yield by about $23 \%$ and polyurethane tubing increased this by a further $32 \%$ ). Thus, using a polyurethane tube and a rinse volume of $20 \mathrm{~mL}$, administration of lansoprazole via NGT can be considered. Pantoprazole is not recommended for administration via NGT unless the dosing procedure is optimized, (eg, by preparing a suspension with one crushed enteric-coated $40 \mathrm{mg}$ pantoprazole tablet and $840 \mathrm{mg}$ of sodium bicarbonate solution, or a suspension containing $40 \mathrm{mg}$ of pantoprazole granules and apple juice). Otherwise, alternative proton pump inhibitor therapy (eg, esomeprazole, an orally disintegrating lansoprazole tablet, intravenous pantoprazole) should be considered..$^{10-12}$

Medications in group 2 have no specific formulation recommendations, but PubMed-based evidence discourages NGT dosing of these medications. A study by Kotake et al showed that serum concentrations of amiodarone and its active metabolite, desethylamiodarone, were $26 \%$ and $31 \%$, respectively, of those treated orally, and the dosage of amiodarone for the patients treated nasogastrically needed to be increased by approximately three-fold. ${ }^{4}$ The lower serum amiodarone levels in patients treated nasogastrically may be attributed to two underlying mechanisms: amiodarone is a highly lipophilic drug and its absorption from the gastrointestinal tract may be decreased when bile is insufficient, and amiodarone may adhere to or be absorbed by the NGT, with only $70 \%$ of the amiodarone dose being recovered at the tube exit. A study by Tisdale et al concluded that nasogastric administration of amiodarone should be avoided for prophylaxis or treatment of tachyarrhythmia following esophagectomy due to the significantly lower serum drug concentrations documented in patients with NGT. ${ }^{13}$ Bass et al described a strong correlation between carbamazepine dose $(\mathrm{mg} / \mathrm{kg})$ and peak plasma concentrations after oral administration but not with NGT administration. ${ }^{14}$ Carbamazepine as a $100 \mathrm{mg} / 5 \mathrm{~mL}$ suspension may bind to polyvinyl chloride feeding tubes, and dilution with an equal volume of diluent before being administered via NGT can prevent this loss. Therapeutic monitoring of amiodarone and carbamazepine is particularly important during NGT dosing.

Errors leading to inappropriate use of medications administered via NGT occurred at multiple levels in our study. Doctors failed to realize that all solid oral formulations given to tube-fed patients would have to be crushed for administration via NGT. Owing to an information design defect, interface of pharmacy management information system still displayed oral administration route despite that medications were prescribed to be given via NGT. Hence, pharmacists could not detect severe pharmacotherapeutic issues in the drug dispensing process. Finally, the nurse who crushed and administered the medications did not understand the rationale for use or characteristics of the medications in group 1 and group 2. Thus, the importance of education and communication needs to be emphasized further among team members regarding basic knowledge about pharmaceutical formulations and the NGT dosing administration procedure.

\section{Evidence supporting NGT administration in groups 3 and 4}

Prescribing information for medications in group 3 note in particular that the medications should not be crushed or opened. However, evidence in the PubMed database supports NGT dosing for these medications. Enteric-coated aspirin formulations should not be crushed or chewed to prevent gastric irritation. There are several lines of indirect evidence supporting NGT dosing of aspirin. Zafar et al reported that aspirin can be delivered in crushed form via NGT soon after coronary artery bypass grafting surgery to prevent graft occlusion. ${ }^{15} \mathrm{~A}$ study by Shennib et al reported on the safety and early efficacy of a combined regimen of clopidogrel $75 \mathrm{mg} /$ day and aspirin $325 \mathrm{mg} /$ day orally or initially through NGT for 3 months, commencing within 6 hours of surgery. ${ }^{2}$ Sandercock et al reviewed antiplatelet therapy methods for acute ischemic stroke and concluded that aspirin $160-300 \mathrm{mg}$ /day given orally (or via NGT in patients who cannot swallow) and started within 48 hours of onset of presumed ischemic stroke can reduce the risk of early recurrent stroke without a major risk of early hemorrhagic complications and improving the long-term outcome. ${ }^{3}$ However, no head-to-head safety and efficacy comparisons of NGT and oral dosing have been published for enteric-coated aspirin formulation as yet.

A study by Sostek et al showed that NGT administration of enteric-coated pellets from an opened capsule containing esomeprazole $40 \mathrm{mg}$ assured complete delivery of drug, in that $\mathrm{AUC}$ and $\mathrm{C}_{\max }$ values were similar to those after oral dosing using the intact capsule. ${ }^{16}$ Administration of esomeprazole via NGT is a practical option for patients with feeding tubes who require effective gastric acid suppression 
but cannot swallow an oral formulation. Moreover, it may provide a reasonable alternative to parenteral administration of proton pump inhibitors for tube-fed patients with functional gastrointestinal tracts. ${ }^{9}$

A case report described successful administration of crushed Sinemet $^{\circledR}$ and amantadine via NGT for perioperative Parkinson's rigidity during emergence from anesthesia. ${ }^{17}$ However, a head-to-head investigation on NGT versus oral dosing is not as yet available for Sinemet.

Clopidogrel has no specific formulation-related dosing recommendations, but PubMed-based evidence supports NGT dosing in light of its potential clinical benefits. A $300 \mathrm{mg}$ loading dose of crushed clopidogrel administered via NGT has faster and greater bioavailability than an equivalent dose given orally as whole tablets. ${ }^{15}$ The median peak plasma concentration reached was $80 \%$ higher with crushed clopidogrel than with whole tablets. The geometric mean time taken to reach peak plasma concentration was 44 minutes with crushed clopidogrel versus 70 minutes for the whole tablets. The AUC at 40 minutes, a measure of early bioavailability, was almost two-fold greater following delivery of crushed clopidogrel than of the oral intact tablet $(P<0.05)$. However, the total AUC for the 24-hour period was similar for crushed clopidogrel versus the intact tablet. Earlier antiplatelet therapy has proven benefits in the treatment of myocardial infarction and in patients undergoing percutaneous coronary intervention. Thus, clopidogrel administration via NGT could have widespread clinical implications.

\section{Questionnaire}

Questionnaire results indicated the following: poor knowledge of pharmaceutical dosage forms on the part of nurses; lack of intervention by pharmacists in this respect; and a dire need for publication of hospital-wide standard operation procedures for nasogastric drug administration by clinical nurses.

Drugs scheduled for dosing at the same time are generally administered using the same syringe, and the mixing of drug preparations is a factor that triggers drug interactions, tube obstruction, and other problems. Also, there is the potential for drug interactions as a consequence of not washing the mortar between crushings of multiple drugs.

Poor awareness of rational nasogastric administration attracted the attention of the Drug and Therapeutics Committee at our hospital in April 2012. The PDCA cycle provides a simple but effective approach for problem-solving and managing change, ensuring that ideas are appropriately tested before being committed to full implementation. Thus, this approach was introduced to address our dilemma. We wanted to achieve a goal of at least 95\% rationality in medical orders and at least a 95\% awareness rate among clinical nurses ("Plan"). Several intervention measures have been taken, including developing a protocol for drug administration via NGT, applying relative informatics technology to the interface between writing medical orders and prescription auditing (eg, online warnings against irrational use and display of administration routes in the pharmacy management information system), educating physicians, pharmacists, and nurses to have basic technical knowledge concerning pharmaceutical formulations, and encouraging all staff with awards to report near misses on NGT medication, while those who are negligent receive extra attention and guidance ("Do"). Also, attention has been paid to problems of instability, interaction with enteral nutrition, adsorption, tube obstruction, and low recovery related to extemporaneously prepared oral suspensions.

In June 2012, we re-evaluated the appropriateness of NGT medication in clinical practice ("Check"). Irrational medical orders involving nasogastric administration of medications in group 1 were successfully abolished. The rate of answering correctly whether medications in group 1 could be crushed or opened increased to $100 \%$. This re-evaluation was the basis for subsequent action and a decision whether the maneuver needed further improvement or whether quality criteria were reached ("Action"). We believe our preliminary intervention was efficient and reached our predefined criteria. Further areas for improvement include management of interaction between enteral nutrition and extemporaneously prepared oral suspensions, and identifying the starting points for research into NGT dosing.

\section{Conclusion}

We performed an evaluation of the appropriateness of administration of medication via the NGT route in a tertiary care teaching hospital. Our results indicate poor awareness of this issue among physicians and nurses. Fortunately, using a PDCA approach, preliminary intervention have been done, which proved to be efficient as a result of team cooperation and effort.

\section{Acknowledgment}

This work was supported by the Zhejiang Provincial Bureau of Health (2012KYA090) and the Zhejiang Provincial Bureau of Education (Y201016850). 


\section{Disclosure}

No conflicts of interest are declared in relation to this work.

\section{References}

1. Schier JG, Howland MA, Hoffman RS, Nelson LS. Fatality from administration of labetalol and crushed extended-release nifedipine. Ann Pharmacother. 2003;37:1420-1423.

2. Shennib H, Endo M, Benhameid O. A feasibility study of the safety and efficacy of a combined clopidogrel and aspirin regimen following off-pump coronary artery bypass grafting. Heart Surg Forum. 2003;6:288-291.

3. Sandercock PA, Counsell C, Gubitz GJ, Tseng MC. Antiplatelet therapy for acute ischaemic stroke. Cochrane Database Syst Rev. 2008;3: CD000029.

4. Kotake T, Takada M, Goto T, Komamura K, Kamakura S, Morishita H. Serum amiodarone and desethylamiodarone concentrations following nasogastric versus oral administration. J Clin Pharm Ther. 2006;31:237-243.

5. Gosgnach M, Aymard G, Huraux C, Fléron MH, Coriat P, Diquet B. Atenolol administration via a nasogastric tube after abdominal surgery: an unreliable route. Anesth Analg. 2005;100:137-140.

6. Jin H, Huang H, Dong W, et al. Preliminary experience of a PDCA-cycle and quality management based training curriculum for rat liver transplantation. J Surg Res. 2012;176:409-422.

7. Carter J. Small-scale study using the PDCA cycle. In: Gift R, Kinney C, editors. Today's Management Methods: A Guide for the Health Care Executive. New York, NY: Wiley, John \& Sons Inc; 1996.

8. Berkovitch M, Dafni O, Leiboviz A, Mayan H, Habut B, Segal R. Therapeutic drug monitoring of theophylline in frail elderly patients: oral compared with nasogastric tube administration. Ther Drug Monit. 2002;24:594-597.
9. Messaouik D, Sautou-Miranda V, Bagel-Boithias S, Chopineau J. Comparative study and optimisation of the administration mode of three proton pump inhibitors by nasogastric tube. Int J Pharm. 2005;299: $65-72$.

10. Ferron GM, Ku S, Abell M, et al. Oral bioavailability of pantoprazole suspended in sodium bicarbonate solution. Am J Health Syst Pharm. 2003;60:1324-1329.

11. Tammara B, Weisel K, Katz A, Meng X. Bioequivalence among three methods of administering pantoprazole granules in healthy subjects. Am J Health Syst Pharm. 2009;66:1923-1928.

12. Ponrouch MP, Sautou-Miranda V, Boyer A, Bourdeaux D, Montagner A, Chopineau J. Proton pump inhibitor administration via nasogastric tube in pediatric practice: comparative analysis with protocol optimization. Int J Pharm. 2010;390:160-164.

13. Tisdale JE, Wroblewski HA, Hammoud ZT, et al. Prospective evaluation of serum amiodarone concentrations when administered via a nasogastric tube into the stomach conduit after transthoracic esophagectomy. Clin Ther. 2007;29:2226-2234.

14. Bass J, Miles MV, Tennison MB, Holcombe BJ, Thorn MD. Effects of enteral tube feeding on the absorption and pharmacokinetic profile of carbamazepine suspension. Epilepsia. 1989;30:364-369.

15. Zafar MU, Farkouh ME, Fuster V, Chesebro JH. Crushed clopidogrel administered via nasogastric tube has faster and greater absorption than oral whole tablets. J Interv Cardiol. 2009;22:385-389.

16. Sostek MB, Chen Y, Skammer W, Winter H, Zhao J, Andersson T. Esomeprazole administered through a nasogastric tube provides bioavailability similar to oral dosing. Aliment Pharmacol Ther 2003; 18:581-586.

17. Stagg P, Grice T. Nasogastric medication for perioperative Parkinson's rigidity during anaesthesia emergence. Anaesth Intensive Care. 2011;39:1128-1130.
Therapeutics and Clinical Risk Management

\section{Publish your work in this journal}

Therapeutics and Clinical Risk Management is an international, peerreviewed journal of clinical therapeutics and risk management, focusing on concise rapid reporting of clinical studies in all therapeutic areas, outcomes, safety, and programs for the effective, safe, and sustained use of medicines. This journal is indexed on PubMed Central, CAS,

\section{Dovepress}

EMBase, Scopus and the Elsevier Bibliographic databases. The manuscript management system is completely online and includes a very quick and fair peer-review system, which is all easy to use. Visit http://www.dovepress.com/testimonials.php to read real quotes from published authors. 